stimulant effect on cardiac muscle, and, as it constricts coronary vessels, should never be used. ${ }^{24}$

As vasoconstriction reduces perfusion of the tissues and is responsible for the irreversibility of shock, ${ }^{18}$ the possible value of inhibiting it with an adrenergic antagonist has recently been investigated. ${ }^{25}$ Phenoxybenzamine in combination with intravenous infusions reduces mortality in haemorrhagic and bacteraemic shock. ${ }^{182627}$ In experimental cardiogenic shock survival was considerably increased by phenoxybenzamine and low-molecular-weight dextran but not by noradrenaline. ${ }^{28} 29$ Phenoxybenzamine and noradrenaline together also gave good results but no better than phenoxybenzamine alone. In cardiogenic shock which follows cardiopulmonary bypass operations for repair of heart defects the high peripheral resistance due to high levels of circulating catechol amines is deleterious to the already weakened heart, and adrenergic antagonists such as phenoxybenzamine have been shown to be beneficial. ${ }^{18} 30$ Phenoxybenzamine has recently been tried and advocated for the treatment of cardiogenic shock in man. ${ }^{31}$ However, as this drug increases the size of the vascular bed, it should be accompanied by transfusion and monitoring of central venous pressure. The natural anxiety to avoid transfusion for patients with reduced cardiac output is possibly overemphasized, as phenoxybenzamine actually reduces the raised central venous pressure in patients with pulmonary oedema.

It is too early to recommend adrenergic antagonists as routine treatment for cardiogenic shock. However, vasopressor drugs have done little to improve the mortality, and their prolonged use is undoubtedly harmful. Phenoxybenzamine will receive increasing attention, though further work will be needed to establish its true value.

\section{Costly Error}

Increases in the pay of university clinical teachers are customarily geared to those periodically awarded by the Review Body to hospital medical staff. This procedure was being followed after the award to N.H.S. doctors in May, and the advice of the University Grants Committee was already under consideration by the Government when the pay-freeze was announced on 20 July. As Dr. K. Zinnemann, Chairman of the B.M.A.'s Full-time Medical Teachers and Research Workers Committee, points out in a letter at p. 527, clinical teachers believed, for reasons which he gives, that the Government was committed to implement as from 1 April whatever salary increases were due to them. This would have put the teachers in the same category as their N.H.S. hospital colleagues in relation to the operation of the incomes standstill.

The Government has now decided, in the light of the considerations set out in the White Paper on Prices and Incomes Standstill, that there should be no increase in clinical teachers' pay. Briefly recapitulating the exchanges at a recent meeting between a B.M.A. deputation and the Minister of State for Education and Science, the Under-Secretary of State for the Department, in a letter printed in the Supplement (p. 116), repeats the Government's view that in " the very strict sense that the context of the White Paper required" there had been no commitment to increase the salaries of teachers as a direct consequence of increases in the pay of hospital medical and dental staff. That means that considera- tion of any increase in clinical teachers' pay must now be postponed at least until the first half of 1967-which the White Paper designates as a period of "severe restraint "- and, to quote the Minister, "would have to be justified under the then incomes policy criteria." These are unlikely to be other than stringent.

The pay-freeze is a clumsy instrument which has been wielded indiscriminately. Like everyone else it has hit, doctors must accept the blow with what fortitude they can (or emigrate). But there seems no valid reason for singling out clinical medical teachers from their colleagues for treatment which can be judged only as unjust, and which will be regarded as such by those in this small but select branch of the profession. It cannot be believed that it was impossible to apply a more lenient interpretation of the "strict" sense of the terms of the White Paper nor that to do so would have cracked, let alone broken, the solidarity of the pay-freeze.

This inept handling of the clinical teachers' case is an error which in the long run is likely to prove costly to British Medicine. Dr. Zinnemann estimates that at least 500 more teachers will be required to staff the urgently needed expansion of the medical schools. In the most favourable circumstance it would be difficult to recruit that number. Now it may well be impossible. The outlook would be slightly less grave if it could be thought that the Government understood the probable consequences of its action. Unfortunately, there is little indication that it does.

\section{The Endothelial Cell}

There has never been any lack of interest by physiologists or pathologists in the endothelial lining of the blood and lymphatic vessels, nor have clinicians been unaware of the importance of this barrier. Nevertheless, it has been customary to think of this lining as " a sheet of nucleated cellophane "- the striking phrase used by Lord Florey in his Roy Cameron Lecture, which is printed at page 487 of this week's B.M.F. Though this concept may have been due in part to the success of Starling's work, it was also the result of ignorance: but knowledge in this field is now advancing rapidly.

The instrument of this revolution in knowledge has been the electron microscope, which first revealed the structure of the vascular wall. The endothelial barrier is now seen as a layer of elongated cells with a full complement of intracellular organelles. The endothelium normally forms a tightly interdigitated layer, but in some places, such as in renal glomeruli, this is not so and the physical integrity of the capillary would appear to depend on the basement membrane.

Continuous passage of molecules of all sorts between blood and tissues is essential for life, and it is not surprising that there is intensive research into the mechanism of this transport. Since molecules leave the blood at a speed roughly

1 Pappenheimer, J. R., Physiol. Rev., 1953, 33, 387.

s Maino, G., and Palade, G. E., F. Biophys. Biochem. Cytol., 1961, 11 , 571 .

4 Cotran, R. S., Amer. F. Path., 1965, 46, 589.

5 Ham, Kathryn N., and Hurley, J. V., f. Path. Bact., 1965, 90, 365

- Hurley, J. V., and Spector, W. G., ibid., 1965, 89, 245.

Miles, A. A., in Wound Healing, ed. Illingworth, C., 1966, Churchin, London.

s Marchesi, V. T., Ann. N.Y. Acad. Sci., 1964, 116, 774.

- Mowans, J. L., Proc. roy. Soc., 1964, $159 \mathrm{~B}, 283$.

10 Courtice, F. C., and Morris, B., Quart. Ұ. exp. Physiol., 1955, 40, 138.

1 Maino, G., in Handbook of Physiology, Section 2, Circulation, vol. 3, Ma)no, G., in Handbook of Physiology, Section 2, Circulation, vol. 3,
p. 2293. Ed. Hamilton, W. F., and Dow, P., 1965, American Physiological Society, Washington. 
inverse to their size, the theory of restricted diffusion through pores of fixed size ${ }^{1}$ was attractive at first sight. However, the failure of electron microscopy to reveal such pores threw the theorists into confusion. Small molecules probably pass through the endothelial cytoplasm by way of general cell transport mechanisms. The situation with regard to larger molecules is very uncertain. Two possibilities seem to exist ; carriage within intracytoplasmic vesicles (caveolae intracellularis) or passage along tight interendothelial junctions, which may relax imperceptibly to allow transfer. One of the best recent experiments quoted by Florey suggests that both mechanisms operate.

In inflammation the permeability of vascular endothelial walls increases enormously so that large amounts of plasma protein escape to form the characteristic protein-rich exudate. ${ }^{2}$ The now classical paper by G. Majno and G. E. Palade ${ }^{3}$ showed conclusively that increased vascular permeability, induced for example by histamine, was due to a short-lived opening up of the normally tight interendothelial junctions. The existence of these gaps in inflammation itself has been shown by R. S. Cotran ${ }^{4}$ and Kathryn N. Ham and J. V. Hurley.5 Junction-opening after application of histamine or bradykinin is largely confined to venules with little apparent effect on true capillaries. ${ }^{3}$ The same may be true at least of some types of injury, ${ }^{6}$ but the relative contribution of venules and capillaries to inflammatory exudates is uncertain and may well be variable. ${ }^{i}$

It is now known, also from electron microscopy, that the leucocytes that enter the tissues in inflammation do so via the interendothelial junctions by inserting pseudopodia into the potential space. ${ }^{8}$ This process may continue in the absence of plasma protein leakage from the affected vessel. ${ }^{6}$ One possible exception to the intercellular route is the intracytoplasmic transport of small lymphocytes reported to occur in normal lymph-node venules."

Another pathological situation in which the vascular endothelium is important is atherosclerosis. This problem may prove to be specially related to the question of the transport of lipid macromolecules across the vessel wall ${ }^{10}$ and is clearly a promising field for research.

As pointed out in Majno's outstanding review, ${ }^{11}$ one of the major issues to be resolved is the discrepancy between the electron microscopic and physiological data concerning the permeability of endothelial walls. When, however, this gap " of only a few Angstroms" $"$ is bridged, the basic problem of the mechanism of junction opening and leucocytic diapedesis after injury will still remain.

\section{Mammography as a Screening Test for Breast Cancer}

Breast cancer in women is the cause of approximately onequarter of cancer deaths and of about three in every 100 deaths from all causes. In spite of improvements in treatment and new methods of palliation there is no evidence that the death rate is decreasing. All experience suggests that the earlier treatment is established the better is the chance of a permanent cure. Many methods have been advocated to encourage early detection; these include selfexamination by the patient, routine clinical examination at special clinics, and recently the use of $x$-ray mammography. ${ }^{1}$
This is a technique for soft-tissue radiography of the breast and can detect malignant tumours which are impalpable on clinical examination.

In December 1963 the Health Insurance Plan of Greater New York, in cooperation with certain medical groups, launched a screening programme for breast cancer by both mammography and clinical examination; and recently $S$. Shapiro, P. Strax, and L. Venet ${ }^{2}$ reported on the first two years' experience of this experiment. Women between the ages of 40 and 64 years taking part in the Health Insurance Plan were randomly allocated to either a control or a study group. Those in the study group were offered a screening examination at their medical centre and encouraged to attend for two similar annual follow-up examinations. The women in the control group followed their usual practice for medical care and no special effort was made to encourage them to be examined. So far, 9,883 examinations have been carried out on the study group, and, either on clinical or on radiological grounds, 227 women have been recommended for a biopsy or an aspiration. Of these, 145 agreed to an operation, and 23 cancers were confirmed by pathological examination. At subsequent mastectomy $16(70 \%)$ of these had no evidence of malignant deposits in the regional lymph nodes. Four further cases of cancer were reported between screening examinations, making a total of 27 cases for the study group. In the control group during a similar period 14 cases of breast cancer occurred, of which eight $(57 \%)$ had no evidence of spread of the disease.

No conclusions are drawn from these preliminary data, and prolonged follow-up, including mortality figures, will be needed for a useful assessment of the results. However, it may be prudent at this stage to consider the value and practicality of mammography as a screening procedure if it were applied to the population in general. Are we likely to see the technique introduced within the next few years and become as important in the detection of breast cancer as the smear for cervical cancer?

There would certainly be considerable difficulties in introducing such a scheme. In the study reported by Shapiro and his colleagues only 13 patients could be examined both clinically and radiologically in a three-hour session. A programme for the general population would create practical and economic problems on a scale that would put it beyond the resources of most countries. In addition to the time and the skilled medical assistance needed for such a service, provision would have to be made for carrying out biopsy procedures on approximately $2 \%$ of those women who were examined. Furthermore, the optimum time for re-examination is not yet known, though it seems likely that the procedures would have to be repeated annually.

For these techniques to be of value some means must be found to recognize a group of women who run an abnormally high risk of developing breast cancer. These women could then be studied at special centres properly equipped for this purpose, and if any tumour was detected either clinically or radiologically then the appropriate steps could be taken. So far no methods exist for identifying such a highrisk group. Though the incidence of breast cancer is

\footnotetext{
1 Stevens, G. M., and Weigen, J. F., Cancer (Philad.), 1966, 19, 51. Shapiro, S., Strax, P., and Venet, L., f. Amer. med. Ass., 1966, 195, 731.

s Bulbrook, R. D., Hayward, J. L., Spicer, C. C., and Thomas, B. S., Lancet, 1962, 2, 1238 .

4 Hayward, J. L., Brit. F. Surg., 1964, 51, 224

- Brit. med. F., 1965, 2, 1198. L. J., Lancet, 1966, 1690.
} 